\title{
A novel breeding programme for improved growth in barramundi Lates calcarifer (Bloch) using foundation stock from progeny-tested parents
}

\author{
Gilbert Michael Macbeth ${ }^{\mathrm{a}, *}$, Paul John Palmer ${ }^{\mathrm{b}}$ \\ a Department of Employment Economic Development and Innovation, Ecosciences Precinct, GPO Box 46, Brisbane, 4001, Australia \\ ${ }^{\mathrm{b}}$ Department of Employment Economic Development and Innovation, Bribie Island Research Centre, 144 North Street, Woorim 4507 Australia
}

\section{A R T I C L E I N F O}

Article history:

Received 6 July 2010

Received in revised form 16 May 2011

Accepted 16 May 2011

Available online 23 May 2011

\section{Keywords:}

Growth rate

Heritability

Progeny test

Asian seabass

Barramundi

Lates calcarifer

\begin{abstract}
A B S T R A C T
Rapid genetic gains for growth in barramundi (Lates calcarifer) appear achievable by starting a breeding programme using foundation stock from progeny tested broodstock. The potential gains of this novel breeding design were investigated using biologically feasible scenarios tested with computer simulation models. The design involves the production of a large number of full-sib families using artificial mating which are compared in common growout conditions. The estimated breeding values of their paternal parents are calculated using a binomial probit analysis to assess their suitability as foundation broodstock. The programme can theoretically yield faster rates of genetic gain compared to other breeding programmes for aquaculture species. Assuming a heritability of 0.25 for growth, foundation broodstock evaluated in two years had breeding values for faster growth ranging from $21 \%$ to $51 \%$ depending on the genetic diversity of stock under evaluation. As a comparison it will take between nine and twenty-two years to identify broodstock with similar breeding values in a contemporary barramundi breeding programme.
\end{abstract}

Crown Copyright @ 2011 Published by Elsevier B.V. All rights reserved.

\section{Introduction}

Barramundi (Lates calcarifer) also known as Asian sea-bass is an increasingly important tropical aquaculture species of the Asia-Pacific region and it is inevitable that breeding programmes for this species will soon commence (Macbeth et al., 2002; Wang et al., 2008). We are not aware of any published papers showing genetic gains for barramundi, and know of only one simulated breeding programme recently reported (Robinson et al., 2010). At the onset of any new breeding programme in aquaculture there is much to be gained by assessing wild genetic diversity as different strains may be more suitable for commercial production. The walk-back selection programme for growth rate proposed by Robinson et al. (2010) does not attempt to evaluate the potentially diverse strains from different geographic locations prior to breeding. In species other than barramundi regional sampling of strains has revealed a $52 \%$ difference between low and high growth in six strains of Labeo rohita (Reddy et al., 2002), a 73\% difference in weight in five strains of Onorhynchus mykiss (Overturf et al., 2003) and a 104\% difference in weight at 105 days between Abbassa and Maryout tilapia strains (Elghobashy, 2001). Differences within lines can also be large with

\footnotetext{
(c) The State of Queensland, Department of Employment, Economic Development and Innovation, 2010.

* Corresponding author at: Centre for Applications in Natural Resource Mathematics, School of Mathematics and Physics, The University of Queensland, Queensland, 4072 Australia. Tel.: +61 733466518 .

E-mail address: Michael.Macbeth@deedi.qld.gov.au (G.M. Macbeth).
}

Brody et al. (1976) reporting differences between the means of half-sibs as large as $30 \%$ of the overall mean in Cyprinus carpio.

If the breeding values of wild fish from different regions could be evaluated prior to establishing a breeding programme then there is the potential to make significant genetic gains. Common practise in barramundi hatcheries is to source replacement broodstock from the wild when required, but some hatcheries are starting to use selected commercially grown fish. As with other aquaculture species a breeding programme is usually initiated with one or perhaps combined strains randomly sampled as foundation parents. To address the uncertainty in strain selection a two stage selection approach has been applied in the past where strains are previously evaluated (Elghobashy, 2001) prior to selecting the best strains for a foundation population. However, this strategy can be costly and can take considerably more time than simply forming a synthetic line of mixed strains. More recently in barramundi there have been attempts to find genetic markers linked to quantitative trait loci (QTL) of economic importance as a potential means of screening foundation broodstock (Wang et al., 2007). However, again this method is costly and is restricted to a small number of QTL with large effects so ignores the potentially largest component of genetic variance from cumulative effects of many genes with smaller effects.

In an alternative strategy the high accuracy of progeny testing (Robertson, 1957) could be used to evaluate wild fish. This strategy has been under consideration for many years since Wohlfarth et al. (1961) used it to assess growth in carp. Later Brody et al. (1976) advocated large scale progeny tests but Gjedrem (1983) suggested that it would "increase generation interval markedly". Five years later Gall (1988) mentioned that there was no evidence that progeny testing had been successfully 
implemented in fish breeding and since then it has received little attention in aquaculture for testing of quantitative traits such as growth rate.

Barramundi is ideally suited to progeny testing because their high fecundity in both females (up to $46 \times 10^{6}$ eggs per female; Davis, 1984) and males (up to $10-15 \mathrm{ml}$ of semen; Maneewong, 1986; Palmer, 2000) allows many progeny to be tested for each parent. Artificial fertilisation would be essential because large numbers of synchronous natural spawns are difficult to achieve in practise for this species. Artificial fertilisation can also eliminate maternal effects and eliminate age differences which could potentially give fish a size advantage they never relinquish (Tave, 1995). We propose screening potential foundation broodstock for growth using genotype identification and phenotypic observations in a progeny test framework where families are produced by artificial fertilisation.

While copious quantities of semen can be collected from wild males captured on spawning grounds, this is generally only possible a short time before spawning in captive males (Hogan et al., 1987). The potential to strip-spawn eggs and artificially inseminate them with cryopreserved semen from multiple sires has been successfully demonstrated in L. calcarifer (Palmer et al., 1993) and enables the progeny of many half-sib families to be grown for accurate breeding value determination of sires. The protandrous sex reversal of $L$. calcarifer (male to female at 3-8 years of age: Davis, 1982; Moore, 1979) offers a novel approach in which wild broodstock females can be accurately evaluated prior to selecting them as foundation parents from progeny testing of their paternal full-sib families. The breeding values of young males can also be determined with relatively high precision by combining information from their own phenotype with the relatively accurate breeding values of their progeny tested sires. Thus, young males can also be evaluated as possible foundation broodstock providing inbreeding is managed.

In general, to manage inbreeding to perhaps less than $1 \%$ per generation (Goddard, 1992; Meuwissen and Woolliams, 1994) many more broodstock are needed for a selective breeding programme compared to the relatively low numbers of broodstock that are needed solely to produce fingerlings for industry. This has perhaps been the most important factor that has hitherto inhibited the establishment of a barramundi breeding programme in Australia. Thus in designing a suitable programme for selective breeding in barramundi, as with other large aquaculture species, it is important to consider minimising broodstock numbers to manage costs while having sufficient numbers to manage inbreeding.

Minimising broodstock numbers is one method of reducing costs but what is perhaps more important is to maximise early genetic gains (Smith, 1978). We explore an option to improve the rate of early genetic gains using a mating plan with intense between-family selection of potential foundation stock accurately identified from progeny testing wild barramundi.

Stochastic computer methods are used to evaluate the progeny test scheme proposed here under a range of simulated parameter values. We examine how a progeny test scheme could be implemented for barramundi to estimate heritability, to assess geographic strains, and to achieve rapid genetic gains while managing inbreeding for long term selection. To assist the successful implementation of the scheme a description of husbandry methods is also presented in detail.

\section{Methods}

This is a computer simulation study with the general breeding design having five basic stages: (i) collect wild males and their milt for use in the progeny test, (ii) evaluate wild broodstock through a progeny test, (iii) select the very best progeny test sires (which change to females) and the very best young males from the progeny test as foundation stock, (iv) multiply the best foundation stock to create sufficient families to manage long term inbreeding and (v) perform ongoing selection in subsequent generations.

\subsection{Progeny test design}

We consider an initial breeding design involving the stripping of eggs from two hatchery females and artificial insemination of multiple sires to initiate a progeny test. The number of progeny tested sires simulated (NPT) was either 50,100 or 200 per dam with no fish between the two progeny test groups being related. In an example with $N P T=50$ and two dams, sires $1 \ldots 50$ were crossed with dam one and sires $51 \ldots$ 100 were crossed with dam two. The number of fingerlings reared to $100 \mathrm{~mm}$ from each dam was kept constant at 60,000 to emulate a small hatchery run with the size of each full-sib family equal to 60,000/NPT. In practise more than 60,000 should be reared to account for mortality from fertilisation to $100 \mathrm{~mm}$ and good husbandry should be used to minimise mortality (see Section 2.8.).

The 60,000 fingerlings from each dam were not mixed at any time. For each dam the $100 \mathrm{~mm}$ fingerlings were then randomly subsampled into two replicates each with a stocking group size (SGS) of $5000,15,000$ or 30,000 resulting in $50,000,30,000$ and none being discarded respectively. The sub-sampling creates some variability in the number in each full-sib family between replicates and emulates a realistic on-farm sampling event. The two replicates were considered a minimum to reduce the risk of experimental failure with only one replicate required to achieve genetic gains.

While the number of barramundi females used in strip spawning (NFS) can be varied to suit a number of experimental designs we demonstrate how a minimum of two dams can be used successfully to achieve large genetic gains. The reason why we chose only two dams is that manual stripping of eggs from a female is a demanding task with precision timing of egg collection required (Palmer, 2000) and to demonstrate that the two dams is sufficient to manage long term inbreeding.

\subsection{Simulation of data}

Assuming the foundation stock were unrelated, the true breeding value $(A)$ was determined using a simulated heritability $\left(h_{s}^{2}\right)$ which was assigned in different simulations as either $0.2,0.25,0.3$ or 0.4 . The equations were simplified by expressing phenotypic variance $\sigma_{P}^{2}=\sigma_{a}^{2}+$ $\sigma_{e}^{2}=1$ giving the additive genetic variance $\sigma_{a}^{2}=h_{s}^{2}$ and the error variance $\sigma_{e}^{2}=1-\sigma_{a}^{2}$. True breeding values for $i=1 \ldots(N P T \times N F S)$ progeny test sires were determined by $A_{i}=N\left(0, \sigma_{a}^{2}\right)$, and the true breeding values for $j=1 \ldots N F S$ dams as $A_{j}=N\left(0, \sigma_{a}^{2}\right)$. True breeding values for the $k^{\text {th }}$ offspring $(k=1 \ldots K)$ from the $i^{\text {th }}$ sire and $j$ th dam were determined by $A_{i j k}=\left(A_{i}+A_{j}\right) / 2+M_{i j k}$ with the Mendelian sampling variation estimated as $M_{i j k}=N\left(0, \sigma_{a}^{2} / 2\right)$. The phenotype of the $i j k^{\text {th }}$ progeny was determined as $P_{i j k}=A_{i j k}+N\left(0, \sigma_{e}^{2}\right)$.

The sensitivity of the progeny test was examined with a different number of full-sibs $(K)$ within each sire $i$ and dam $j$ combination. Using $N P T=50$, we simulated (a) even full-sib family size $K=1200$ yielding 60,000 fingerlings which were randomly sorted into two replicates of 30,000, (b) variable full-sib family size using five groups of 10 progeny tested sires each with $K$ equal to $1920,1560,1200,840$ and 480 yielding 60,000 fingerlings which were random sorting into two replicates of 30,000 and (c) variable full-sib family survival from $100 \%$ to $40 \%$ using five groups of 10 progeny tested males each with $K$ equal to $1200,1080,960,840$ and 720 yielding 48,000 fingerlings prior to random sorting into two replicates of 24,000 . In option (c) total survival is assumed to be known with progeny breeding values determined using $S G S=24,000$ samples. Due to random sampling into two replicate groups the number of full-sibs per family was approximately $K / 2$ in each replicate. For each combination of parameters simulated the progeny test was repeated in 250 computer trials each with two replicates. 


\subsection{Geographic sampling}

Here we examine the effectiveness of the progeny test to identify superior strains collected from genetically isolated populations in the wild. In this study we simulate five strains with populations having mean genetic differences $\mu$ equal to $-2,-1,0,1$ or 2 standard deviations for growth in a commercial environment. When modelling regional sampling we used $N P T=50$ sires comprising 10 sires per strain sampled within each of the two spawning groups. The genetic value of the $i^{\text {th }}$ progeny tested sire was expressed as $A_{i}=N\left(0, \sigma_{a}^{2}\right)+\mu$.

\subsection{Statistical analysis}

Estimation of heritability and estimated breeding values were calculated using a probit sire model which is essentially the "threshold" model in animal breeding (Gianola and Foulley, 1983). The threshold point was determined by the heaviest number genotyped $(N G)$ using either 200, 400 or 800 fish selected on phenotype at final harvest for each replicate within each dam. The $N G$ fish were genotyped with sire identified (and thus also assigned to its full-sib family) and the record assigned a threshold score of one. Records for all remaining fish, the stocking group size (SGS) less the heaviest genotyped $(N G)$, were created and assigned a threshold score of zero by assuming each sire contributed to SGS/NPT full-sib samples in total. In the case where variable family sizes were modelled we still assumed equal full-sib contributions per sire when setting up the analysis as the unequal contributions were assumed to be unknown. Variance parameters were estimated by residual maximum likelihood (REML) by defining the binary score as the random effect in package ASREML (Gilmour et al., 2001) with heritability from the probit analysis calculated as: $h^{2}=4 \sigma_{s}^{2} /\left(\sigma_{s}^{2}+1\right)$ where $\sigma_{s}^{2}$ is the estimated sire variance. In matrix notation the model can be written as $y=Z a+e$ where $y$ is a vector containing threshold scores of zero or one, $a$ is a vector of additive genetic effects of sires, $Z$ is the incidence matrix relating random sire effects to observations and $e$ is a vector of random errors.

The estimated mean and standard deviation $\left(\sigma_{h^{2}}\right)$ of $h^{2}$ were determined from 500 simulation trials. Assuming the average $h^{2}$ estimate was determined from the mean of four estimates obtained from each of two dams by two replicate groups, the standard error of the mean $h^{2}$ was determined as: $\sigma_{h^{2}} / \sqrt{4}=\sigma_{h^{2}} / 2$.

\subsection{Evaluation of foundation broodstock}

The estimated breeding values from the $i^{\text {th }}$ progeny tested sire $\left(\hat{A}_{i}\right)$ was obtained from the $\sin$ output file of ASREML (Gilmour et al., 2001). Pre-stocking tank effects (effects prior to $100 \mathrm{~mm}$ ) were not simulated and assumed to be non-significant as fingerlings are in practise graded and mixed between tanks up to ten times. We assume all variation prior to stocking is non-genetic with procedures put in place to minimise phenotypic variation (Section 2.8). As barramundi are protandrous hermaphrodites the best wild-captured progeny tested sires, identified as those with the highest $\hat{A}_{i}$ values for harvest weight, change sex to functional females. To speed up selection response we use young males reared from the progeny test as foundation males (first generation sires) and mate them to the best progeny tested sires which are now females. Within each dam the estimated breeding value of the $i k^{\text {th }}$ progeny ( $k$ th full-sib from the $i$ th progeny tested sire) was estimated as: $\hat{A}_{i k}=\hat{A}_{i} / 2+i_{i k} h^{2}(1-r) /$ $\sqrt{\left(1-r . h^{2}\right)}$ where $h^{2}$ is the heritability, $r=0.5$ is the genetic coancestry for full-sibs and $i_{i k}$ is the within-family selection differential in phenotypic standard deviation units. In practise the weight from all offspring from a dam are not individually recorded with $i_{i k}$ estimated using $i_{i k}=\left(P_{i k}-\bar{P}\right) / \sigma_{P}-\hat{A}_{i} / 2$ where $\hat{A}_{i}$ is the estimated breeding value of the $i^{\text {th }}$ sire determined from the probit sire model, $P_{i k}$ is the harvest weight of the $i k^{\text {th }}$ male and the phenotypic mean $(\bar{P})$ and variance $\left(\sigma_{P}^{2}\right)$ of offspring weights determined from sampling. For all simulations we used $\bar{P}=0$ and $\sigma_{P}=1.0$ with $i_{i k}=P_{i k}-\hat{A}_{i .} / 2$.

\subsection{Ongoing selection response}

After establishment of the progeny test, which is only implemented in the initial generation to assess breeding values of foundation broodstock, ongoing selection was deployed in all following generations using within-family selection. This design assumed a selection intensity of 1:1000 ( $i=3.37$ standard deviations) with 24 families and a cumulative inbreeding rate restricted to $1 /(2 \mathrm{Ne})=0.52 \%$ per generation where effective population size $\mathrm{Ne}=2 \mathrm{~N}$ (Falconer, 1972) given variance in family size is zero and $N=2 \times 24$ parents. For illustrative purposes long-term genetic improvement was expressed as the improvement in two-year harvest weight of $2.5 \mathrm{~kg}$, heritability $h^{2}=0.25$, a coefficient of variation of $25 \%$ (consistent with $19.7 \%$ and $27.6 \%$ in barramundi; Wang et al., 2008) and a generation length of three years. Using these parameters a deterministic rate of within-family selection response was estimated as $i \sigma_{P} h^{2}(1-r) / \sqrt{\left(1-r \cdot h^{2}\right)}=0.55$ genetic standard deviations (Falconer, 1972).

\subsection{Inbreeding}

Coefficients of inbreeding of the different designs were determined using methods described in Meuwissen and Luo (1992) implemented in the Animal Breeder's Tool Kit (Golden et al., 1992).

\subsection{Implementation of progeny test design and husbandry}

We believe that a practical design would consist of the collection of at least 100 wild males (e.g. NPT $=50$ for each of two dams) from an assortment of geographic regions and possibly including some broodstock males from industry. This collection would be undertaken during their summer spawning season, so that semen can be simultaneously harvested and cryopreserved in liquid nitrogen. We suggest that semen is stored in several (at least two) separate cryovials per male ( $0.2 \mathrm{ml}$ per vial: Palmer et al., 1993). All males are pit tagged and held in captivity pending estimated breeding value (EBV) assessment for each sire using the progeny test scheme. At this stage, males in captivity should be screened for noda virus (Parameswaran et al., 2008) by testing semen and blood taken at time of capture or other strategic times during transfer and handling.

Matings for the progeny test are created using the cryopreserved semen of 2NPT wild males and strip-spawned eggs from two induced females. These are arranged using a controlled insemination process which creates two unrelated groups of NPT full-sib families. Two induced females are seen as a minimum for management of inbreeding. The strip spawning process is made easier through the use of hatchery females with a track record of consistent spawning under repeatable environmental conditions. Females with oocyte diameters of about $0.4 \mathrm{~mm}$ can be induced to spawn with single aqueous injections of luteinising hormone-releasing hormone analogues (Garcia, 1989; Garrett and Connell, 1991). Under optimal conditions ovulation generally occurs $36-38 \mathrm{~h}$ after injection, which allows stripping times to be predicted. Using this approach Palmer (2000) achieved multiple successful artificial inseminations using a mechanically-assisted approach to the mixing of stripped eggs and thawed cryopreserved semen. According to this design fertilisation is performed simultaneously in separate chambers each containing one cryovial of thawed semen $(0.2 \mathrm{ml})$ and $20 \mathrm{ml}$ of eggs for each full-sib family. The "dry" method of fertilisation is used where semen and eggs are mixed before an equal volume of seawater is added to activate the sperm and inseminate the eggs. At 3000 eggs $\mathrm{ml}^{-1}$ and 50\% mortality from unfertilised and unhatched eggs, this approach would yield approximately 30,000 larvae per full-sib family. Using this procedure we create two unrelated groups with each group having a different mother and NPT different fathers. These two groups are not mixed during the progeny test and are reared separately. 
Table 1

Average heritability $\left(h^{2}\right)$ and (standard deviation) from $500 h^{2}$ estimates determined by simulating $N G=400$ genotyped and $N P T=50$ progeny tested sires. The standard error of the average heritability $( \pm)$ was determined from four estimates derived from two strip spawns each with two replicates.

\begin{tabular}{|c|c|c|c|c|c|}
\hline \multirow[b]{3}{*}{$\begin{array}{l}\text { Stocked } \\
(S G S)\end{array}$} & \multicolumn{5}{|l|}{ Simulated heritability $\left(h_{s}^{2}\right)$} \\
\hline & 0.2 & 0.3 & & 0.4 & \\
\hline & \multicolumn{5}{|l|}{ Estimated heritability $\left(h^{2}\right)$} \\
\hline 15,000 & $0.200 \quad(0.058) \pm 0.029$ & 0.302 & $(0.072) \pm 0.036$ & 0.406 & $(0.094) \pm 0.048$ \\
\hline 30,000 & $0.199(0.059) \pm 0.030$ & 0.300 & $(0.076) \pm 0.038$ & 0.413 & $(0.089) \pm 0.043$ \\
\hline
\end{tabular}

About 10 min after mixing with seawater the inseminated eggs are incubated in aerated 3 litre hemispherical bowls until the embryos hatch. This approach allows fertilisation rates to be assessed during the pre-hatch incubation period. Subsequent viability estimates for each bowl can assist in determining the volumetric stocking that can provide approximately equal numbers of hatched larvae from each full-sib family into a communal larval rearing facility. Appropriate biosecurity measures could be applied, such as the disinfection of fertilised eggs with ozonated water to reduce the incidence of infections including noda-viruses and infectious pancreatic necrosis virus (Grotmol et al., 2003).

Barramundi fingerlings typically require grading when they reach a length of $20 \mathrm{~mm}$ to avoid cannibalism which occurs when size differences are greater than 67\% (Parazo et al., 1991). Gradings may then be required as often as every three to seven days with all fish pooled and sorted on size (girth) into about five tanks. As fish grow and during each grading process the same five tanks are used to reallocate the separate grades. The variance of fingerling size could be minimised by suppressing growth in larger grades using tank temperatures lower than their optimum $28^{\circ} \mathrm{C}$ to $32{ }^{\circ} \mathrm{C}$ range (Glencross and Felsing, 2006). For example Bermudes et al. (2010) reported differential growth rates in fingerlings with temperatures below $29^{\circ} \mathrm{C}$. The lower phenotypic variance will reduce the need to cull outlier fingerlings to retain approximately the same number in each full-sib family group. At $30 \mathrm{~mm}$ size the fingerlings are transferred to larger grow-out facilities with grading continued where necessary until they reach $100 \mathrm{~mm}$. At this length communal stocking for growth assessment occurs.

We propose a final mechanical grading at around $250 \mathrm{~g}$ to manage competition and cannibalism. The heaviest $20 \%$ of individuals are restocked for final growout, preferably until a commercial harvest weight of up to $2.5 \mathrm{~kg}$ (or 2 years), with the remaining fish discarded. The heaviest number genotyped $(N G)$, within each of the two dams and two replicates, are held in captivity for $E B V$ assessment after being pit-tagged, weighed, and tissue sampled for sire identification using genotyping. Caudal fin clips provide non-destructive tissue samples for this identification procedure (Frost et al., 2006).

\section{Results}

\subsection{Heritability}

Heritability $\left(h^{2}\right)$ estimates using a binomial probit analysis from genotyping the heaviest (largest) $N G$ progeny were consistent with the simulated heritability (Table 1 ). This confirms that the probit analysis is a suitable way of determining heritability for continuous traits such as harvest weight and that the simulation is implemented correctly.

\subsection{Genetic gains}

The progeny test was used to evaluate potential foundation stock prior to the commencement of a breeding programme. We first determine if a variation in the size of each full-sib family $(K)$ has an impact on breeding value estimation. In practise the true breeding values are not known but as this is a simulation we can view the true breeding values from the best animals selected on estimated breeding values from the binomial probit analysis. The average true breeding values of the best progeny-tested fish ranked on $\left(\hat{A}_{i}\right)$ and the best young males within each full-sib family ranked on $\left(\hat{A}_{i j k}\right)$ from one replicate are shown in Table 2 . The results indicate that the progeny test is a robust evaluation method. The large variation in full-sib family size (Table $2 \mathrm{~b}$ and c) had little effect on the true breeding values of both young males and progeny tested sires compared to no variation in family size (Table 2a). In these runs the best progeny-tested (PT) dams (originally wild males) had breeding values that were less variable than the best young males. The accuracy of breeding value determination for the first generation young males was higher than what could be achieved without pedigree information of $h=\sqrt{0.30}=0.55$.

The phenotype $P_{i j k}$ of the top eight young males averaged 3.15, $3.10,3.05,3.08,3.02,3.02,3.03$ and 2.98 phenotypic standard deviations in the control (Table 2a) with 50 full-sib families of approximately even size of $\approx 600$ at harvest. If the top four of these young males were selected the selection intensity would be 3.10 phenotypic standard deviations. The phenotypes of young males in models of Table $2 \mathrm{~b}$ and c were similar to those of Table $2 \mathrm{a}$ reported above. If the top four PT dams were selected from the 50 tested, the selection intensity would be $8 \%$.

The results from Table $2 \mathrm{a}$ have common simulated variables that can be compared with different stocking group size (SGS), simulated

Table 2

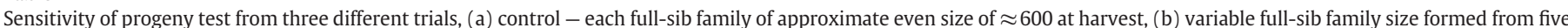

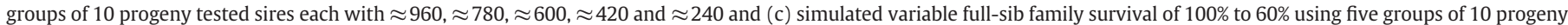

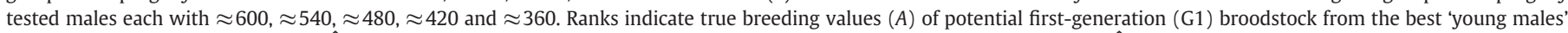

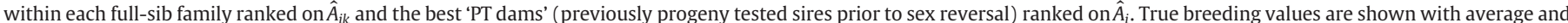

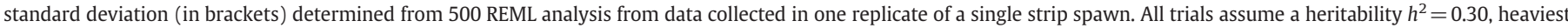

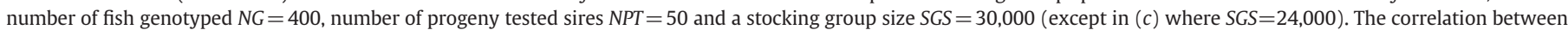
true breeding values and estimated breeding values $\left(r_{A, \hat{A}}\right)$ are also listed.

\begin{tabular}{|c|c|c|c|c|c|c|c|c|c|}
\hline Rank & 1 & 2 & 3 & 4 & 5 & 6 & 7 & 8 & $r_{A, \hat{A}}$ \\
\hline \multicolumn{10}{|l|}{ (a) } \\
\hline Young males & $1.11(0.46)$ & $1.00(0.46)$ & $0.97(0.45)$ & $0.90(0.45)$ & $0.82(0.44)$ & $0.85(0.44)$ & $0.82(0.45)$ & $0.78(0.46)$ & 0.62 \\
\hline PT dams & $1.18(0.29)$ & $0.97(0.25)$ & $0.84(0.23)$ & $0.76(0.24)$ & $0.70(0.23)$ & $0.63(0.23)$ & $0.60(0.22)$ & $0.52(0.24)$ & 0.87 \\
\hline \multicolumn{10}{|l|}{ (b) } \\
\hline Young males & $1.12(0.54)$ & $0.99(0.56)$ & $0.95(0.56)$ & $0.92(0.54)$ & $0.86(0.55)$ & $0.85(0.53)$ & $0.81(0.53)$ & $0.78(0.53)$ & 0.62 \\
\hline PT dams & $1.16(0.30)$ & $0.97(0.25)$ & $0.84(0.24)$ & $0.77(0.25)$ & $0.68(0.23)$ & $0.64(0.23)$ & $0.57(0.24)$ & $0.54(0.24)$ & 0.87 \\
\hline \multicolumn{10}{|l|}{ (c) } \\
\hline Young males & $1.11(0.47)$ & $0.97(0.45)$ & $0.89(0.45)$ & $0.86(0.46)$ & $0.83(0.44)$ & $0.81(0.45)$ & $0.80(0.45)$ & $0.79(0.45)$ & 0.61 \\
\hline PT dams & $1.17(0.29)$ & $0.93(0.26)$ & $0.82(0.24)$ & $0.75(0.22)$ & $0.66(0.23)$ & $0.60(0.24)$ & $0.56(0.23)$ & $0.52(0.25)$ & 0.86 \\
\hline
\end{tabular}


Table 3

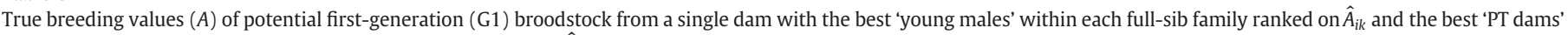

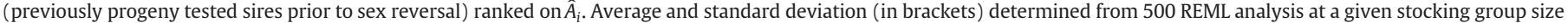

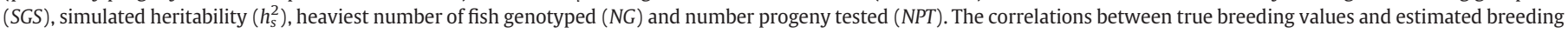
values $\left(r_{A, \hat{A}}\right)$ are also listed.

\begin{tabular}{|c|c|c|c|c|c|c|c|c|c|c|}
\hline & rank & 1 & 2 & 3 & 4 & 5 & 6 & 7 & 8 & $r_{A, \hat{A}}$ \\
\hline \multicolumn{11}{|c|}{$\begin{array}{l}\text { (a) Changing SGS with } h_{s}^{2}=0.30, N G=400 \text { and } N P T=50 \\
\text { SGS }\end{array}$} \\
\hline \multirow[t]{2}{*}{5,000} & Young males & $1.03(0.46)$ & $0.90(0.47)$ & $0.83(0.46)$ & $0.80(0.47)$ & $0.79(0.47)$ & $0.72(0.47)$ & $0.73(0.46)$ & $0.71(0.48)$ & 0.60 \\
\hline & PT dams & $1.12(0.34)$ & $0.90(0.29)$ & $0.79(0.28)$ & $0.73(0.28)$ & $0.64(0.29)$ & $0.61(0.27)$ & $0.57(0.28)$ & $0.52(0.28)$ & 0.83 \\
\hline \multirow[t]{2}{*}{15,000} & Young males & $1.10(0.46)$ & $0.95(0.46)$ & $0.94(0.45)$ & $0.87(0.43)$ & $0.83(0.43)$ & $0.80(0.43)$ & $0.78(0.43)$ & $0.74(0.44)$ & 0.62 \\
\hline & PT dams & $1.16(0.34)$ & $0.94(0.27)$ & $0.83(0.25)$ & $0.74(0.25)$ & $0.69(0.24)$ & $0.61(0.25)$ & $0.56(0.24)$ & $0.51(0.24)$ & 0.86 \\
\hline \multicolumn{11}{|c|}{$\begin{array}{l}\text { (b) Changing } h_{s}^{2} \text { with } D N A=400, N P T=50 \text { and } S G S=30,000 \\
h_{s}^{2}\end{array}$} \\
\hline \multirow[t]{2}{*}{0.20} & Young males & $0.84(0.39)$ & $0.73(0.37)$ & $0.68(0.38)$ & $0.64(0.37)$ & $0.58(0.39)$ & $0.59(0.37)$ & $0.56(0.42)$ & $0.53(0.39)$ & 0.56 \\
\hline & PT dams & $0.94(0.25)$ & $0.77(0.23)$ & $0.66(0.21)$ & $0.60(0.21)$ & $0.54(0.23)$ & $0.50(0.22)$ & $0.46(0.22)$ & $0.41(0.22)$ & 0.83 \\
\hline \multirow[t]{2}{*}{0.40} & Young males & $1.42(0.52)$ & $1.27(0.52)$ & $1.21(0.51)$ & $1.17(0.52)$ & $1.08(0.52)$ & $1.10(0.52)$ & $1.08(0.51)$ & $1.01(0.52)$ & 0.67 \\
\hline & PT dams & $1.38(0.31)$ & $1.15(0.26)$ & $1.00(0.25)$ & $0.89(0.24)$ & $0.81(0.23)$ & $0.74(0.23)$ & $0.68(0.23)$ & $0.63(0.24)$ & 0.89 \\
\hline \multicolumn{11}{|c|}{$\begin{array}{l}\text { (c) Changing } N G \text { with } h_{s}^{2}=0.30, N P T=50 \text { and } S G S=30,000 \\
N G\end{array}$} \\
\hline \multirow[t]{2}{*}{200} & Young males & $1.11(0.45)$ & $0.98(0.46)$ & $0.93(0.47)$ & $0.89(0.47)$ & $0.85(0.44)$ & $0.83(0.46)$ & $0.82(0.46)$ & $0.79(0.45)$ & 0.60 \\
\hline & PT dams & $1.16(0.31)$ & $0.94(0.27)$ & $0.81(0.26)$ & $0.71(0.27)$ & $0.66(0.26)$ & $0.61(0.25)$ & $0.54(0.27)$ & $0.49(0.27)$ & 0.81 \\
\hline \multirow[t]{2}{*}{800} & Young males & $1.12(0.47)$ & $1.04(0.48)$ & $0.94(0.47)$ & $0.91(0.46)$ & $0.87(0.46)$ & $0.84(0.46)$ & $0.85(0.45)$ & $0.79(0.46)$ & 0.63 \\
\hline & PT dams & $1.21(0.28)$ & $1.00(0.25)$ & $0.88(0.22)$ & $0.78(0.22)$ & $0.70(0.22)$ & $0.64(0.21)$ & $0.59(0.20)$ & $0.54(0.20)$ & 0.92 \\
\hline \multicolumn{11}{|c|}{$\begin{array}{l}\text { (d) Changing NPT with } h_{s}^{2}=0.30, N G=400 \text { and } S G S=30,000 \\
N P T\end{array}$} \\
\hline \multirow[t]{2}{*}{100} & Young males & $1.15(0.44)$ & $1.06(0.47)$ & $1.00(0.45)$ & $0.98(0.44)$ & $0.90(0.46)$ & $0.90(0.44)$ & $0.88(0.47)$ & $0.82(0.44)$ & 0.60 \\
\hline & PT dams & $1.27(0.31)$ & $1.10(0.26)$ & $0.97(0.26)$ & $0.88(0.25)$ & $0.83(0.26)$ & $0.79(0.26)$ & $0.76(0.25)$ & $0.70(0.26)$ & 0.80 \\
\hline \multirow[t]{2}{*}{200} & Young males & $1.15(0.48)$ & $1.04(0.47)$ & $0.99(0.46)$ & $0.96(0.46)$ & $0.90(0.47)$ & $0.89(0.46)$ & $0.91(0.46)$ & $0.88(0.46)$ & 0.58 \\
\hline & PT dams & $1.30(0.32)$ & $1.14(0.30)$ & $1.04(0.31)$ & $0.97(0.32)$ & $0.90(0.30)$ & $0.87(0.31)$ & $0.84(0.31)$ & $0.82(0.31)$ & 0.69 \\
\hline
\end{tabular}

heritability $\left(h_{s}^{2}\right)$, number genotyped $(N G)$ and number of progeny tested sires per dam (NPT) presented in Table 3. If foundation broodstock were selected from the top four ranked sires (young males grown during the progeny test) and top four ranked PT dams within each of the two 30,000 stocked spawning groups (Table 2a) the 16 breeding values would be superior to the sampled wild population by $0.97 \pm 0.09$ phenotypic standard deviations for weight at harvest (or approximately $24 \%$ faster growth assuming a coefficient of variation of $25 \%$ ). In the case where each stocking group size (SGS) was reduced to 15,000 the improved broodstock from the top four males and females was reduced to $0.89 \pm 0.10$ phenotypic standard deviations (Table 3a).

The breeding values of young males were more sensitive to a reduction in heritability than the progeny tested dams. When 30,000 fingerlings $(100 \mathrm{~mm})$ were stocked into the growout system and the simulated heritability was reduced from $h^{2}=0.30$ (Table 2a) to $h^{2}=0.20$ (Table $3 \mathrm{~b}$ ) the true breeding values of first-ranked young males were reduced by $38 \%$ while the true breeding values of firstranked progeny-tested dams were reduced by $26 \%$.

Increasing the number genotyped per dam from 200 to 800 increased the combined breeding values of the top four ranked young males and top four PT dams by 5\% (Table 3c).

Theoretically more than 50 sires per dam can yield higher genetic gains (Table 2a and Table 3d). Compared to using 200 sires per dam
(Table 3d) instead of 50 sires (Table 2a) the average of the top four young males and top four PT dams improved by $9 \%$.

\subsection{Genetic gains from geographic sampling}

The true breeding values were significantly higher in Table 4 than those in Tables 2 and 3 because the genetic merit of superior strains was detected through the progeny test. The breeding values of all sires in Table 4 were lower than the best geographic region $(\mu=2)$ as their mother used in the strip spawn had an average breeding value of zero and contributed half her genes to the sires. Additional genetic response could be achieved by sampling (and possibly re-evaluating) foundation sires from the best performing geographic region. Even though more progeny test sires would theoretically yield a higher response (Table $3 \mathrm{~d}$ ) the simulations presented in Table 4 were derived using a more manageable 50 sires per dam.

If foundation broodstock were selected from the top four ranked sires (young males grown during the progeny test) and the top four ranked PT dams within each of the two spawning groups the 16 breeding values would average $2.12 \pm 0.09$ phenotypic standard deviations better than the average strain (Table 4 ) and be approximately 53\% faster growing assuming a coefficient of variation of $25 \%$ and $h^{2}=0.30$.

When simulating a heritability of 0.25 the 16 breeding values averaged $2.05 \pm 0.09$ phenotypic standard deviations or $51 \%$ faster

Table 4

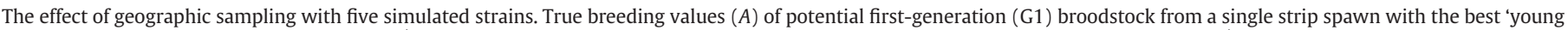

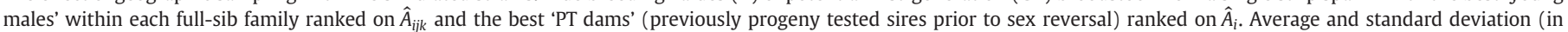

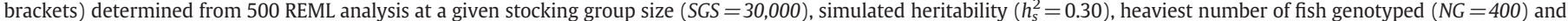
number progeny tested $(N P T=50)$. The correlation between true breeding values and estimated breeding values $\left(r_{A, \hat{A}}\right)$ are also listed.

\begin{tabular}{|c|c|c|c|c|c|c|c|c|c|}
\hline Rank & 1 & 2 & 3 & 4 & 5 & 6 & 7 & 8 & $r_{A, \hat{A}}$ \\
\hline Young males & $1.90(0.46)$ & $1.78(0.45)$ & $1.69(0.44)$ & $1.62(0.44)$ & $1.56(0.46)$ & $1.51(0.45)$ & $1.47(0.46)$ & $1.39(0.47)$ & 0.86 \\
\hline PT dams & $2.82(0.32)$ & $2.55(0.29)$ & $2.35(0.26)$ & $2.21(0.25)$ & $2.08(0.24)$ & $1.98(0.26)$ & $1.88(0.25)$ & $1.74(0.27)$ & 0.92 \\
\hline
\end{tabular}


growth $(N P T=50, S G S=30,000, N G=400)$ with $r_{A \hat{A}}$ equal to 0.86 and 0.92 for young males and PT dams respectively.

\subsection{Managing inbreeding for long-term selection response}

In order to maximise genetic gains it is necessary to balance the need to select the very best evaluated fish with the need to minimise the number required to manage inbreeding at below $1 \%$ per generation (Goddard, 1992; Meuwissen and Woolliams, 1994). A mating plan that satisfies this inbreeding constraint was designed (Appendix A); it uses 16 founding fish comprising four of the best sires and four of the best dams from each of the two spawning groups. This breeding plan is one of many alternatives and requires a wild backcross which we call generation G1.5. The progeny from the backcross are multiplied into 24 families which are maintained in subsequent generations with two offspring per family contributing to each generation. The 24 families are formed during the multiplication phase (see Appendix A) by selecting six parents from each of eight full-sib families produced from the 16 founding parents.

The mating plan in the Appendix A assumes all eight first-generation sires being related to the first generation dams. Our simulated results showed that these eight sires will only be related to all first generation dams $7 \%$ of the time $\left(h_{\mathrm{s}}^{2}=0.30, N G=400, N P T=50, S G S=30,000\right)$ with this increasing to $21 \%$ when genetic strains were modelled. Constraining the best first generation sires (young males from the progeny test) so that none are related to first generation dams reduced inbreeding. This also reduced the selection response in the first generation by $16 \%$ and $7 \%$ of gains made with 15,000 and 30,000 fish stocked respectively with one strain sampled, $h_{\mathrm{s}}^{2}=0.30, N G=400$ and $N P T=50$. Cumulative inbreeding is expected to lie within the two extremes shown in Fig. 1 with longterm inbreeding accumulating at the rate of $0.52 \%$ per generation. With 24 families inbreeding can be completely avoided up until 3.5 generations where different levels of relatedness from the sampling of sires and dams create two divergent patterns (Fig. 1). Fig. 1 also indicates the extrapolation of the long term inbreeding rate back to generation zero which is an estimate of the cost of the progeny test in terms of inbreeding and is estimated to be $1.0 \%$ to $2.5 \%$. This means that the theoretical asymptotic selection response would be $97.5 \%$ to $99.0 \%$ compared to the response from our within-family selection programme had the progeny test not been used to evaluate and multiply superior foundation broodstock.

\subsection{Long-term selection response}

The additive components of selective improvement from progeny testing followed by within-family selection are illustrated in Fig. 2.

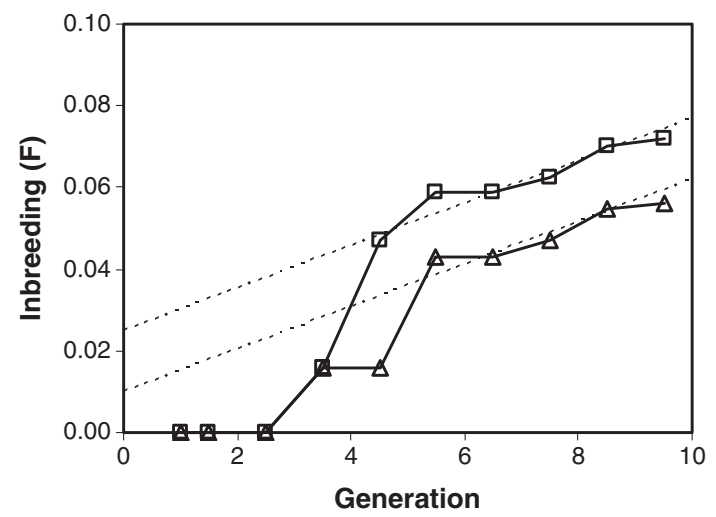

Fig. 1. Average inbreeding level over the first 10 generations of selective breeding assuming none $(\triangle)$ or all $(\square)$ of the eight sires (young males from the progeny test) in the first generation were related to the eight progeny test dams. The dashed line illustrates the long term inbreeding rate at $0.52 \%$ per generation showing the cost of the progeny test at between $1.0 \%$ and $2.5 \%$ inbreeding at generation zero.

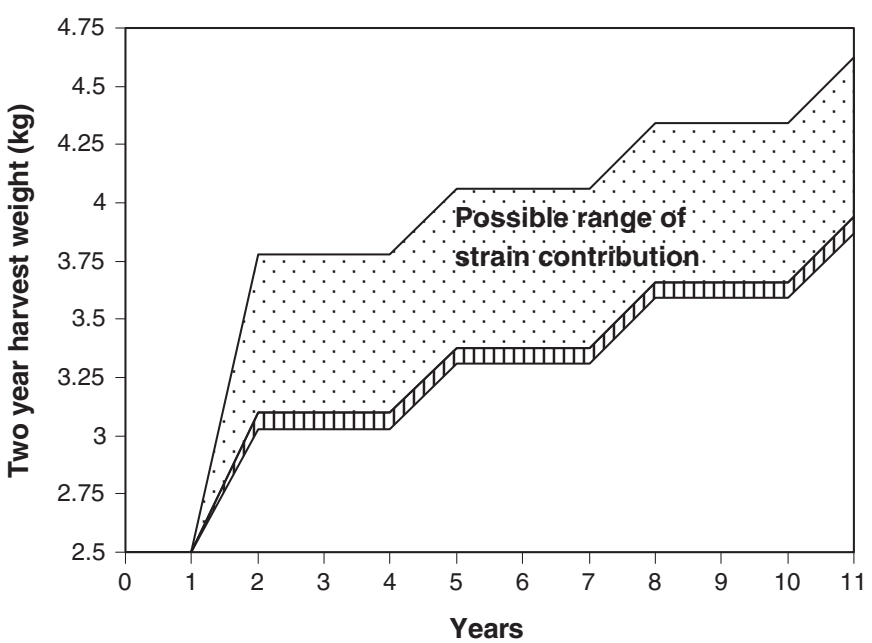

Fig. 2. Broodstock breeding values for two-year harvest weight from the progeny test showing the range of expected improvement from geographical sampling (area with dots) and the cumulative improvement from a within-family selection programme using a high selection intensity of 1:1000 and a generation length of three years. The optional additive gains from sourcing strip-spawned donor females from one round of selection (area with horizontal lines) are included. Simulated parameters were: $h_{\mathrm{s}}^{2}=0.25, N G=400, N P T=50, S G S=30,000$ and a coefficient of variation of $25 \%$.

The improvement shown in this graph assumes a similar mating design to that shown in the Appendix A with the top four males and top four females from each of the two dams used as foundation stock.

The genetic contribution of each dam donor is one-eighth of the founding population genotypes (Appendix A) and one round of selection of these females contributes a small component of total genetic gains (Fig. 2). A large component of the progeny test gains came from the ability to identify superior strains from diverse geographic locations. The foundation population had true breeding values for faster growth, shown in year two of Fig. 2 of between 21\% (no strain differences) and $51 \%$ (with strain differences) of the base population.

\section{Discussion}

There is nothing new about progeny testing in aquaculture (Wohlfarth et al., 1961) or in using artificial mating to estimate genetic parameters (Dupont-Nivet et al., 2008). What is novel in this study is the way we combine strain evaluation, genetic parameter estimation and progeny testing to evaluate potential foundation broodstock using a carefully controlled mating design.

The necessity to regularly grade barramundi until they reach a size of about $250 \mathrm{~g}$ makes traditional genetic parameter estimation challenging. This problem was overcome by sampling only the heaviest animals for genetic parameter estimation and using a binomial probit analysis which also enabled an accurate progeny test evaluation of the best sires.

Also novel is the way we multiply accurately evaluated animals to manage inbreeding with the object of obtaining rapid genetic gains not seen in any other fish breeding design as the between-family selection intensity of $8 \%$ achieved in the first generation of our breeding design is much higher than what is conventionally achieved.

\subsection{Heritability}

Using natural matings, where eggs and sperm are released by the fish directly into the water column of the spawning tank, Wang et al. (2008) estimated the heritability of harvest weight for barramundi as $0.22 \pm 0.16$ and $0.25 \pm 0.18$ from two factorial crosses. These heritability estimates could have been underestimated due to selective culling of graded fingerlings (Blonk et al., 2010). Despite the short duration of the progeny 
test design it gave a more precise heritability estimate of $0.30 \pm 0.04$ from simulated data as many more sires could be evaluated in an experimental design that also minimised the variance in sib numbers.

\subsection{Genetic gains}

The upper range of genetic gains predicted by our models was due to geographic sampling of wild strains. Large differences between strains are possible (Elghobashy, 2001; Overturf et al., 2003). Using the difference between two tilapia strains of $87 \mathrm{~g}$ and $178 \mathrm{~g}$ (Elghobashy, 2001 ) and assuming a $25 \%$ heritability, a $25 \%$ coefficient of variation and estimating the phenotypic standard deviation from the average weight of these strains, the difference between the two strains in genetic standard deviations is equal to 5.5. Similar calculations from five strains of 0 . mykiss (Overturf et al., 2003) revealed 4.1 genetic standard deviations between the fastest and slowest growing strains fed ad libitum. Our simulations assumed a maximum strain difference of 4 genetic standard deviations. Considering the estuarine spawning of semi-isolated populations of barramundi that occurs over $8000 \mathrm{~km}$ along the northern Australian coastline (Chenoweth et al., 1998; Keenan, 1994; Shaklee and Salini, 1985), with the species distribution extending across the Indo-Pacific region (Norfatimah et al., 2009; Yue et al., 2009), we believe the weight range in our simulated strains is a realistic upper limit of what could be expected. The magnitude of strain differences in barramundi is of course impossible to predict without experimental trials.

What is known with greater precision is the genetic gains expected from the progeny test assuming no strain differences and known heritability. In an alternative barramundi breeding programme designed with a different set of constraints Robinson et al. (2010) reported a 7.1\% gain per generation. Our progeny test design (Fig. 2) is capable of identifying in just two years superior broodstock with breeding values that could take between, 3.0 and 7.2 generations to achieve with this alternative design, or 9 to 22 years assuming a three year generation interval.

The reason why our programme works so well in the first generation is that (i) it can manage a much higher between-family selection intensity compared to what can be managed in subsequent generations in any other contemporary design with little effect on inbreeding when utilised with our mating design, (ii) the progeny test is more accurate than first generation phenotypic selection used in all other contemporary designs, particularly when the heritability is low, and (iii) the upper range of genetic response from the progeny test was due to the ability to select the most favourable alleles from the best performing strains, rather than crossing strains prior to evaluation. In this way we have formed an elite foundation population from the best wild strains.

\subsection{Managing inbreeding for long-term selection response}

There are challenges in rearing barramundi in captivity and strip spawning and artificial fertilisation is yet another challenge. However, previous work has proven its feasibility (Palmer et al., 1993). It is likely that after the progeny test artificial fertilisation will only be used sparingly and only when necessary to manage desired family matings that could not otherwise be achieved naturally.

Perhaps the largest challenge in achieving a desirable long-term response to selection is to manage inbreeding through natural mating. A possible mating plan given in the Appendix A illustrates how inbreeding can be minimised through chosen family matings. In practise more flexibility in mating design may be required. After the multiplication phase (see Appendix A), the long-term inbreeding can be managed by following two simple rules: manage individual matings so that inbreeding is less than $25 \%$ and use two different parents in each of the 24 families to contribute to the next generation.

Managing inbreeding using walk-back selection (Sonesson, 2005) may not be practical in barramundi due to the difficulty in synchronising spawns and the highly variable sire contribution rate (Frost et al., 2006). The challenge is exacerbated as barramundi are cannibalistic (Parazo et al., 1991) and it may not be practical to mix families of ages more than one day old as they may have a size advantage they never relinquish (Tave, 1995). This is one reason why we propose the simpler withinfamily selection design for barramundi utilising a very high selection intensity (1:1000) which can theoretically yield genetic gains of $11.4 \%$ per generation $\left(C V=25 \%, h^{2}=25 \%\right)$.

\subsection{Managing matings for long term selection with protandry (sex change)}

A further improvement to the current design could be achieved if the sex of the protandrous broodstock were closely monitored. Assuming 24 families, and perhaps three to four fish per family maintained as potential broodstock, we should be able to start matings as soon as sufficient numbers of females are available. It would not matter if two males (or two females) were selected from one family so long as the long term inbreeding rate is minimised by using two parents per family to contribute to each generation. Short term inbreeding can be managed by avoiding the mating of close relatives. The advantage of this approach is that it can be applied to minimise generation length from 3 years (males 2 years and females 4 years) to perhaps 2.5 years, potentially yielding a further $20 \%$ improvement in the rate of genetic gain. To improve the chances of detecting functional young females more (perhaps three to four) broodstock per family would be useful in this protandry mating design.

\subsection{Cost considerations in design}

The cost of running aquaculture breeding programmes is high, particularly for species with large broodstock size such as barramundi, with costs increasing in proportion to the size of broodstock facilities required to maintain the programme. We designed the progeny test scheme to select foundation stock, using high-intensity betweenfamily selection as a one-off procedure. The scheme continues with a long-term within-family selection programme using only 24 families. As such the scheme achieves significant selective gains over few generations while minimising the number of broodstock that have to be maintained, hence capping the costs of the breeding programme which leads to larger discounted net returns.

As an alternative to long-term within-family selection, it is possible to implement between-family selection at a later stage to allow selection for traits that can only be recorded on sacrificed fish. However, this design would cost several times more because more broodstock are required, and as such, would require an economic assessment of additional costs and projected returns prior to a decision being made on its implementation. In comparison with the model proposed by Robinson et al. (2010) which requires 100-200 broodstock (50-100 full-sib families) our design would require 72-96 broodstock assuming we maintained three to four broodstock per family to guarantee selection of two offspring from each of the 24 families. Therefore the costs of maintaining broodstock in our programme could be as little as half of that proposed by Robinson et al. (2010). In addition, after the progeny test phase, our programme does not require the on-going costs and logistical problems associated with genotyping using walk-back selection.

\section{Conclusion}

The $L$. calcarifer progeny test design described in this paper theoretically identifies superior foundation broodstock in two years. The same level of genetic improvement could take nine to 22 years of selection in other proposed barramundi breeding programmes. Despite the extra effort involved in sourcing potential foundation stock for the progeny test, and the challenging nature of the husbandry activities that 
are required, our scheme compares favourably with the risks that accrue over a much longer time frame that would otherwise be needed to provide similar benefits in contemporary designs.

\section{Acknowledgements}

The progeny test approach was inspired from discussions with Dr Roger Lewer while he was an employee of the Queensland Department of Primary Industries and Fisheries. Thanks to the many useful comments from referees and reviewers. Funding support was provided by the Department of Employment, Economic Development and Innovation.

\section{Appendix A}

A mating design that manages inbreeding over 11 generations is illustrated in Fig. A. The inbreeding rates in each generation from this design are the same as those illustrated within the main text (Fig. 1) which assumes an average generation length from natural mating of

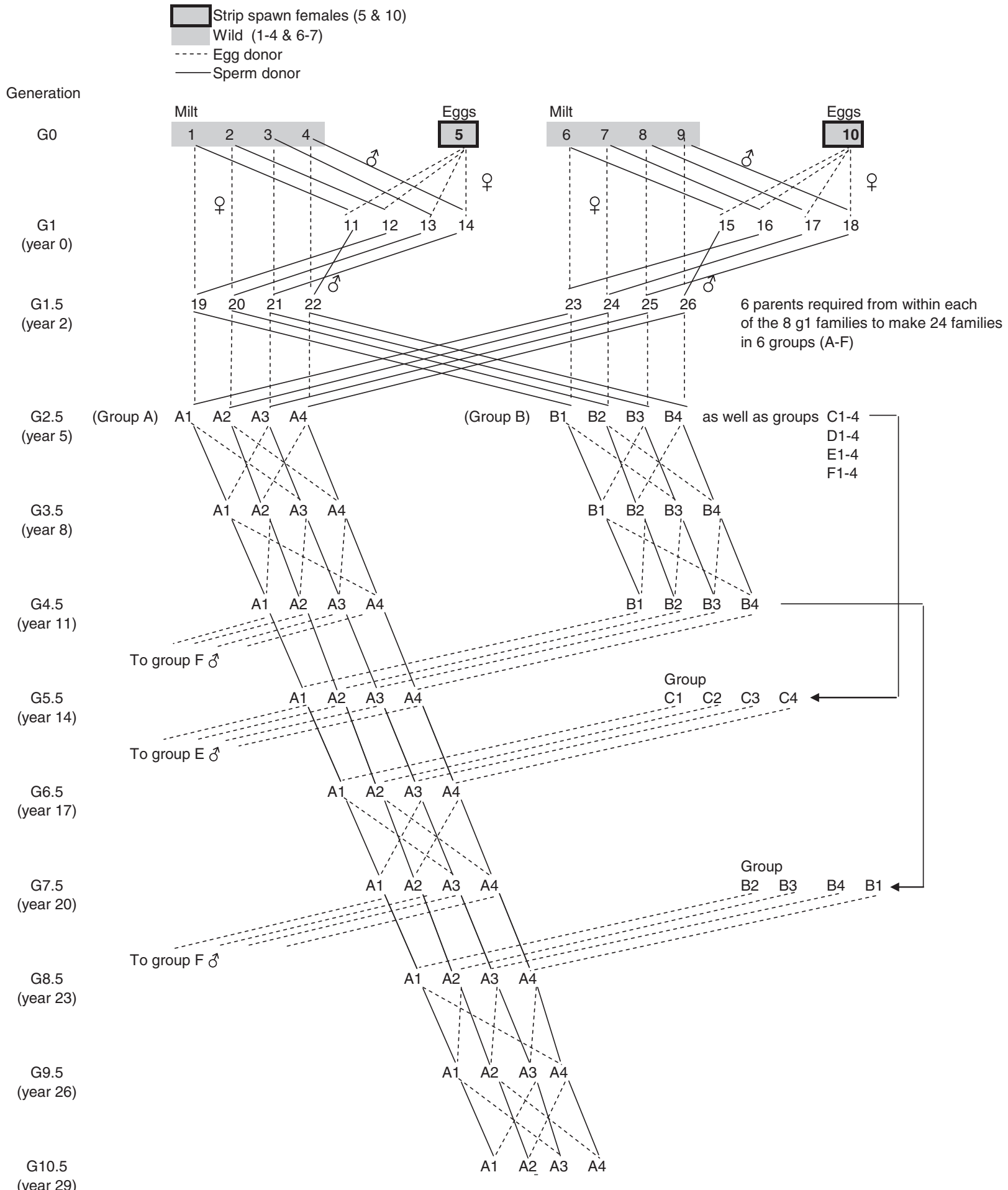

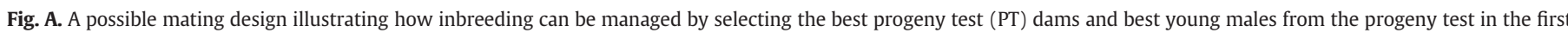
generation (G1) with multiplication of families occurring in the backcross generation in year two (G1.5). 
three years. The mating design is broken down into five phases with a brief description of each given below.

\section{A.1. Generation 0 (collection phase)}

Collection of fish for the progeny test which is made up of two hatchery females (for use in strip spawning) and 100 males chosen from the wild (industry males could also be evaluated from semen collected).

\section{A.2. Generation 1 (progeny test phase)}

Progeny are created from the eggs of two dams artificially mated with semen from 100 wild unrelated males using 50 of these per spawn. Only the best four wild males from each dam (males 1, 2, 3, 4 and $6,7,8,9$ ) are selected for future breeding at harvest weight.

\section{A.3. Generation 1.5 (foundation phase -8 families)}

At two years of age four young males with the highest EBVs are selected within each of the two 50 full-sib family groups from first generation (G1 males 11, 12, 13, 14 and 15, 16, 17, 18). The former wild males with the highest EBVs, now progeny-tested wild females, (G0) are backcrossed to the young males to create a total of 8 foundation families numbered 19 to 26 . The response from the backcross reflects 1.5 generations of selection and therefore we call it G1.5 with the next generation with both parents from G1.5 called G2.5.

\section{A.4. Generation 2.5 (multiplication phase - 24 families)}

Six animals are selected as broodstock replacements from within each of the 8 foundation families in G1.5. This yields 48 broodstock fish $(6 \times 8=48)$, or 24 broodstock pairs to produce 24 families for ongoing selection. The families are divided into six groups (A, B, C, D, $\mathrm{E}, \mathrm{F})$ each containing four families.

\section{A.5. Generation 3.5 onwards (ongoing selection phase -24 families)}

There are many mating designs possible. We show how matings can be made between groups and also within groups to manage inbreeding and minimise gene flow between groups to improve biosecurity risks. As indicated one male and one female are used from each family (within-family mating design). The mating design is flexible; for example, two male parents from one family could be mated to two females from other families. This system accrues inbreeding at a rate of $0.52 \%$ per generation.

\section{References}

Bermudes, M., Glencross, B., Austen, K., Hawkins, W., 2010. The effects of temperature and size on the growth, energy budget and waste outputs of barramundi (Lates calcarifer). Aquaculture 306, 160-166.

Blonk, R.J.W., Komen, H., Kamstra, A., van Arendonk, J.A.M., 2010. Effects of grading on heritability estimates under commercial conditions: a case study with common sole, Solea solea. Aquaculture 300, 43-49.

Brody, T., Moav, R., Abramson, Z.V., Hulata, G., Wohlfarth, G., 1976. Applications of electrophoretic genetic markers to fish breeding. II. Genetic variation within maternal half-sibs in carp. Aquaculture 9, 351-365.

Chenoweth, S.F., Hughes, J.M., Keenan, C.P., Lavery, S., 1998. Concordance between dispersal and mitochondrial gene flow: isolation by distance in a tropical teleost, Lates calcarifer (Australian barramundi). Heredity 80, 187-197.

Davis, T.L.O., 1982. Maturity and sexuality in barramundi, Lates calcarifer (Bloch), in the Northern Territory and South-eastern Gulf of Carpentaria. Australian Journal of Marine Freshwater Research 33, 529-545.

Davis, T.L.O., 1984. Estimation of fecundity in barramundi, Lates calcarifer (Bloch), using an automatic particle counter. Australian Journal of Marine Freshwater Research 35, 111-118.

Dupont-Nivet, M., Vandeputte, M., Vergnet, A., Merdy, O., Haffray, P., Chavanne, H., Chatain B., 2008. Heritabilities and GxE interactions for growth in the European sea bass (Dicentrarchus labrax L.) using a marker-based pedigree. Aquaculture 275, 81-87.
Elghobashy, H., 2001. Aquaculture genetics research in Egypt. p. 29-34. In: Gupta, M.V., Acosta, B.O. (Eds.), Fish genetics research in member countries and institutions of the International Network on Genetics in Aquaculture: ICLARM Conf. Proc., 64. $179 \mathrm{pp}$.

Falconer, D.S., 1972. Introduction to quantitative genetics. Oliver and Boyd, Edinburgh. Frost, L.A., Evans, B.S., Jerry, D.R., 2006. Loss of genetic diversity due to hatchery culture practices in barramundi (Lates calcarifer). Aquaculture 261, 1056-1064.

Gall, G.A.E., 1988. Heritability and selection schemes for rainbow trout: female reproductive performance. Aquaculture 73, 57-66.

Garcia, L.Ma.B., 1989. Spawning response of mature female sea bass, Lates calcarifer (Bloch), to a single injection of luteinizing hormone-releasing hormone analogue: effect of dose and initial oocyte size. Journal of Applied Ichthyology 5, 177-184.

Garrett, R.N., Connell, M.R.J., 1991. Induced breeding of barramundi. Austasia Aquaculture $5,10-12$.

Gianola, D., Foulley, J.L., 1983. Sire evaluation for ordered categorical data with a threshold model. Genetic Selection Evolution 15, 201-224.

Gilmour, A.R., Cullis, B.R., Welham, S.J., Thompson, R., 2001. ASREML User's Manual. New South Wales Agriculture, Orange Agricultural Institute, Orange, NSW, Australia.

Gjedrem, T., 1983. Genetic variation in quantitative traits and selective breeding in fish and shellfish. Aquaculture 33, 51-72.

Glencross, B.D., Felsing, M., 2006. Influence of fish size and water temperature on the metabolic demand for oxygen by barramundi, Lates calcarifer (Bloch), in freshwater. Aquaculture Research 37, 1055-1062.

Goddard, M.E., 1992. Optimal effective population-size for the global population of black-and-white dairy-cattle. Journal of Dairy Science 75, 2902-2911.

Golden, B.L., Snelling, W.M., Mallinckrodt, C.H., 1992. Animal breeder's tool kit user's guide and reference manual. Colorado State Univ. Colorado State University Agricultural Experimental Station Technical Bulletin. LTB92-2.

Grotmol, S., Dahl-Paulsen, E., Totland, G.K., 2003. Hatchability of eggs from Atlantic cod, turbot and Atlantic halibut after disinfection with ozonated seawater. Aquaculture $221,245-254$.

Hogan, A.E., Barlow, C.G., Palmer, P.J., 1987. Short-term storage of barramundi sperm. Australian Fisheries 46, 18-19.

Keenan, C.P., 1994. Recent evolution of population structure in Australian Barramundi, Lates calcarifer (Bloch): an example of isolation by distance in one dimension. Australian Journal of Marine Freshwater Research 45, 1123-1148.

Macbeth, M., O'Brien, L., Palmer, P., Lewer, R., Garrett, R., Wingfield, M., Knibb, W., 2002. Selective breeding in Barramundi: Technical Report for the Australian Barramundi Farmers Association. Department of Primary Industries.

Maneewong, S., 1986. Induction of spawning in sea bass (Lates calcarifer) in Thailand. In: Copland, J.W., Grey, D.L. (Eds.), Management of wild and cultured sea bass/ barramundi (Lates calcarifer): Proceedings of an international workshop held in Darwin, N.T. Australia, 24-30 September 1986, pp. 116-119 (ACIAR Proceedings No. 20).

Meuwissen, T.H.E., Luo, Z., 1992. Computing inbreeding coefficients in large populations. Genetics, Selection, Evolution 24, 305-313.

Meuwissen, T.H.E., Woolliams, J.A., 1994. Effective sizes of livestock populations to prevent a decline in fitness. Theoretical and Applied Genetics 89, 1019-1026.

Moore, R., 1979. Natural sex inversion in giant perch (Lates calcarifer). Australian Journal of Marine Freshwater Research 30, 803-813.

Norfatimah, M.Y., Siti Azizah, M.N., Othman, A.S., Patimah, I., Jamsari, A.F.J., 2009. Genetic variation of Lates calcarifer in Peninsular Malaysia based on the cytochrome b gene. Aquaculture Research 40, 1742-1749.

Overturf, K., Casten, M.T., LaPatra, S.L., Rexroad III, C., Hardy, R.W., 2003. Comparison of growth performance, immunological response and genetic diversity of five strains of rainbow trout (Onorhynchus mykiss). Aquaculture 217, 93-106.

Palmer, P.., 2000. Gamete storage and culture techniques for the barramundi, Lates calcarifer (Bloch). PhD Thesis, The University of Queensland.

Palmer, P.J., Blackshaw, A.W., Garrett, R.N., 1993. Successful fertility experiments with cryopreserved spermatozoa of Barramundi, Lates calcarifer (Bloch) using dimethylsulfoxide and glycerol as cryopreservants. Reproduction, Fertility, and Development 5, 285-293.

Parameswaran, V., Rajesh Kumar, S., Ishaq Ahmed, V.P., Sahul Hameed, A.S., 2008. A fish nodavirus associated with mass mortality in hatchery-reared Asian Sea bass, Lates calcarifer. Aquaculture 275, 366-369.

Parazo, M.M., Aliva, E.M., Reyes Jr., D.M., 1991. Size-dependent and weight-dependent cannibalism in hatchery-bred sea bass (Lates calcarifer Bloch). Journal of Applied Ichthyology 7, 1-7.

Reddy, P.V.G.K., Gjerde, B., Tripathi, S.D., Jana, R.K., Mahapatra, K.D., Gupta, S.D., Saha, J.N., Sahoo, M., Lenka, S., Govindassamy, P., Rye, M., Gjedrem, T., 2002. Growth and survival of six stocks of rohu (Labeo rohita, Hamilton) in mono and polyculture production systems. Aquaculture 203, 239-250.

Robertson, A., 1957. Optimal group size in progeny testing and family selection. Biometrics 13, 442-450

Robinson, N.A., Schipp, G., Bosmans, J., Jerry, D.R., 2010. Modelling selective breeding in protandrous, batch-reared Asian sea bass (Lates calcarifer, Bloch) using walkback selection. Aquaculture Research 41, e643-e655.

Shaklee, J.B., Salini, J.P., 1985. Genetic variation and population subdivision in Australian barramundi, Lates calcarifer (Bloch). Australian Journal of Marine and Freshwater Research 36, 203-218.

Smith, C., 1978. The effect of inflation and form of investment on the estimated value of genetic improvement in farm livestock. Animal Production 26, 101-110.

Sonesson, A., 2005. A combination of walk-back and optimum contribution selection in fish: a simulation study. Genetics, Selection, Evolution 37, 587-599.

Tave, D., 1995. Selective breeding programmes for medium-sized fish farms. FAO Fisheries Technical Paper 352. 
Wang, C.M., Zhu, Z.Y., Lo, L.C., Feng, F., Lin, G., Yang, W.T., Li, J., Yue, G.H., 2007. A microsatellite linkage map of barramundi, Lates calcarifer. Genetics 175, 907-915.

Wang, C.M., Lo, L.C., Zhu, Z.Y., Lin, G., Feng, F., Li, J., Yang, W.T., Tan, J., Chou, R., Lim, H.S., Orban, L., Yue, G.H., 2008. Estimating reproductive success of brooders and heritability of growth traits in Asian sea bass (Lates calcarifer) using microsatellites. Aquaculture Research 39, 1612-1619.
Wohlfarth, G., Moav, R., Lahman, M., 1961. Genetic improvement of carp. III. Progeny tests for differences in growth rate, 1959-60. Bamidgeh 13, 40-54.

Yue, G.H., Zhu, Z.Y., Lo, L.C., Wang, C.M., Lin, G., Feng, F., Pang, H.Y., Li, J., Gong, P., Liu, H.M., Tan, J., Chou, R., 2009. Genetic variation and population structure of Asian seabass (Lates calcarifer) in the Asia-Pacific region. Aquaculture 293, 22-28. 